\title{
Educação para a água
}

\author{
DENISE DE LA CORTE BACCI \\ e ERMELINDA MOUTINHO PATACA
}

\section{Introdução}

A ÁGUA tem fundamental importância para a manutenção da vida no planeta, e, portanto, falar da relevância dos conhecimentos sobre a água, em suas diversas dimensões, é falar da sobrevivência da espécie humana, da conservação e do equilíbrio da biodiversidade e das relações de dependência entre seres vivos e ambientes naturais.

A presença ou ausência de água escreve a história, cria culturas e hábitos, determina a ocupação de territórios, vence batalhas, extingue e dá vida às espécies, determina o futuro de gerações. Nosso planeta não teria se transformado em ambiente apropriado para a vida sem a água. Desde a sua origem, os elementos hidrogênio e oxigênio se combinaram para dar origem ao elemento-chave da existência da vida.

Em condição privilegiada, deu possibilidade às espécies de evoluírem e ao homem de existir e habitar esse planeta. Ao longo de milhares de anos, nossa espécie ocupou territórios, cresceu e desenvolveu com base nesse bem natural tão importante e valioso que é a água. No entanto, ao longo da história, modificações aconteceram na relação do homem com a natureza e, por conseqüência, na sua relação com a água.

$\mathrm{Na}$ sociedade em que vivemos, a água passou a ser vista como recurso hídrico e não mais como um bem natural, disponível para a existência humana e das demais espécies. Passamos a usá-la indiscriminadamente, encontrando sempre novos usos, sem avaliar as conseqüências ambientais em relação à quantidade e qualidade da água.

Somada ao aumento populacional em escala mundial no último século, a intensidade da escassez aumentou em determinadas regiões do planeta, especialmente por fatores antrópicos ligados à ocupação do solo, à poluição e contaminação dos corpos de águas superficiais e subterrâneos.

Em nossa sociedade, a exploração dos recursos naturais, dentre eles a água, de forma bastante agressiva e descontrolada, levou a uma crise socioambiental bastante profunda. Hoje deparamos com uma situação na qual estamos ameaçados por essa crise, que pode se tornar um dos mais graves problemas a serem enfrentados neste século.

Crise essa embasada numa multiplicidade de aspectos - sociais, econômicos, culturais, tecnológicos e ambientais - retratados no aumento da pobreza, na falta de saneamento básico, na poluição dos rios e aqüíferos, na derrubada das matas, 
na expansão agropecuária, na urbanização e industrialização, na ocupação das áreas de mananciais, na má gestão dos recursos hídricos disponíveis. Crise deflagrada pela visão de mundo centrada no utilitarismo dos bens naturais, a qual é descrita por diversos autores, dentre eles, Soffiati (1992), Grün (1996), Carvalho (2004), Loureiro (2004), Guimarães $(2004,2006)$ e no modo de desenvolvimento escolhido pela sociedade e suas relações atuais com o ambiente (Jacobi, 1999, 2005).

Segundo Tundisi (2006), o desenvolvimento econômico e a complexidade da organização das sociedades humanas produziram inúmeras alterações no ciclo hidrológico e na qualidade da água, a qual é afetada até mesmo pelas atividades de cunho religioso.

A resolução de problemas complexos, como a miséria, a proliferação de desastres ambientais, a escassez de recursos naturais, dentre outros, configura-se como um desafio que tem mobilizado cientistas, políticos e membros de comunidades de todas as regiões do planeta.

A água é um tema amplo e pode ser tratado a partir de diferentes enfoques. No presente artigo, optamos por tratar a educação para água a partir de duas dimensões: espacial e temporal (esta última tratando o tempo geológico e a história humana). A decisão de abordar a educação para a água a partir dessas dimensões se dá pelo fato de que sem elas não é possível enfrentar a fragmentação do conhecimento que predomina no ambiente escolar, impedindo a análise integrada de problemas reais, dificultando a relação de conceitos, procedimentos e atitudes nas diferentes disciplinas.

Nessa perspectiva, faz-se necessário compreender a relação homem-natureza ao longo do tempo.

\section{Fragmentações sociais e disciplinares}

A crise à qual nos referimos é resultado de um longo processo de apropriação e destruição da natureza, que se intensificou profundamente com o desenvolvimento do capitalismo industrial, baseado na apropriação da natureza. A produção tecnológica, sustentáculo do capitalismo, se fundamenta no desenvolvimento científico, configurando a sociedade moderna caracterizada por uma extrema fragmentação social e cultural em que o conhecimento se apresenta cada vez mais compartimentado.

O que teria levado à fragmentação do conhecimento e da sociedade? Como poderíamos buscar soluções de articulação entre os saberes? É possível integrar o conhecimento em práticas escolares? Acreditamos que tais questões possam ser respondidas quando abordadas de uma forma contextualizada, relacionando tempo e espaço na produção do conhecimento, de modo a compreendermos o processo de fragmentação dos saberes e a criação de novas práticas e atitudes. Dessa forma, a história das ciências em associação com a educação ambiental pode servir como uma metodologia de ensino que revele uma complexidade de fatores que condicionaram a situação atual e que possa indicar caminhos de reflexão e de elaboração de novas possibilidades para a inversão do contexto atual. 
A transição entre o feudalismo e a sociedade moderna, marcada pelo desenvolvimento do mercantilismo, ocorreu de uma forma lenta e bastante heterogênea nos países europeus desde o século XV. A sociedade comercial que emergia trazia necessidades práticas para seu desenvolvimento e requisitou, cada vez mais, a construção de máquinas e de artefatos aliados ao desenvolvimento da matemática e, conseqüentemente, a quantificação da natureza. O homem voltou-se cada vez mais para a observação da natureza, com uma finalidade prática e utilitarista que permitisse a acumulação de capital. A construção do conhecimento baseava-se, então, em uma forte relação entre ciência e técnica, a fim de solucionar a demanda de instrumentos tecnológicos advinda da sociedade em transformação (Rossi, 1989).

Esse processo de transformação social formulou também um novo método científico. Durante a Idade Média, a natureza era interpretada predominantemente mediante princípios da Escolástica, ou seja, a construção de teorias sobre a natureza era baseada exclusivamente na leitura e interpretação da Bíblia. Durante o Renascimento, o novo contexto imposto pelo mercantilismo impõe uma nova relação do homem com a natureza. A necessidade de matéria-prima para o funcionamento das relações comerciais conduz a uma observação direta da natureza e ao experimentalismo.

O princípio do utilitarismo era a principal justificativa para o estudo da natureza, como preconizado por Francis Bacon, pois revelaria formas de apropriação e utilização dos seres dos três Reinos da Natureza (minerais, vegetais e animais), da ocupação territorial, da dominação humana e da intensa utilização dos recursos hídricos. Dessa forma, a ciência deveria proporcionar o desenvolvimento material da sociedade, relacionando o estudo da natureza com as formas de produção.

A valorização das atividades práticas e da construção de máquinas, necessárias ao desenvolvimento dos núcleos urbanos, à produção de mercadorias em larga escala, ao desenvolvimento da navegação pela construção de instrumentos mais precisos de medida de latitude e longitude, condicionou uma nova forma de observação do universo. Nesse contexto, a utilização da água determinou a expansão territorial e se associou a uma nova concepção de mundo. $\mathrm{O}$ desenvolvimento da navegação, necessário para uma expansão comercial e territorial pretendida pelos países europeus, requisitava o conhecimento sobre o clima, sobre a hidrografia, a astronomia e a matemática. Dessa forma, o homem moderno se voltou para a observação direta da natureza e para o conhecimento de seu funcionamento que possibilitasse sua utilização material.

A metáfora de um universo-máquina foi utilizada pelos filósofos, especialmente René Descartes, como uma nova forma de interpretação da natureza, em que o funcionamento do universo dependia de cada uma de suas partes. Para a compreensão do funcionamento da máquina, o universo poderia ser dividido em várias partes (ou peças) isoladas, que posteriormente seriam rearticuladas para o entendimento do todo. 
Alguns filósofos, porém, especialmente franceses no século XVIII, como D'Alembert, defendiam uma forma organicista de observar a natureza, ou seja, o universo era imaginado como um organismo, cujo funcionamento ocorria num todo integrado. Assim como o corpo humano ou os organismos vivos, o funcionamento se dava em uma relação equilibrada entre as partes (Abrantes, 1998).

A concepção mecanicista teve uma grande influência no desenvolvimento das ciências naturais, configurando-se especialmente no Iluminismo durante o século XVIII. Tal pressuposto acarreta a divisão da natureza em partes cada vez menores, multiplicando a fragmentação da ciência. Francis Bacon já idealizava uma divisão do conhecimento, estruturada em três grandes grupos: memória (história), razão (filosofia ou ciência) e imaginação (poesia, ou artes como concebido atualmente). O que é entendido hoje como ciência relacionava-se à razão e à memória, onde ambas eram divididas em três partes: a ciência de Deus, a ciência do homem e a ciência da natureza.

Por sua vez, a história era dividida em sagrada, civil e natural. Já havia outras subdivisões no conhecimento, o que nos leva a observar o início da fragmentação do conhecimento. Porém, até o século XVIII, os filósofos não dissociavam as questões naturais das humanas, e o mesmo pensador abordava todas as questões e investigava objetos relacionados à natureza ou às relações humanas. Portanto, até esse momento não havia ocorrido, ainda, a especialização do conhecimento.

Foi após a Revolução Industrial que o movimento de especialização ou fragmentação do conhecimento tornou-se mais intenso. A divisão social do trabalho em nossa sociedade contemporânea levou a uma fragmentação cada vez mais intensa do conhecimento em várias disciplinas isoladas, que se relacionam, muitas vezes, aos diversos setores da produção industrial. A própria sociedade fragmentou-se em grupos sociais distintos, tornando-se cada vez mais desigual e heterogênea.

A ética antropocêntrica influenciou profundamente a educação moderna, o que foi sentido na reformulação dos currículos, os quais eram inspirados basicamente nas idéias baconianas em que a natureza tinha claramente um valor utilitarista. Além disso, no século XIX, o mundo comercializado e industrializado exigia a presença das ciências no currículo, essa vista a partir da racionalidade, $\mathrm{o}$ que contribuiu para perpetuar a idéia de natureza objetificada (Grün, 1996).

O pragmatismo, o individualismo e o racionalismo, pilares do pensamento curricular norte-americano, fundamentam-se em éticas utilitárias, que consideram a natureza apenas quanto ao seu valor de uso e de que a educação consiste somente nos indivíduos e sua aprendizagem, como se não houvesse natureza (Grün, 1996).

No início do século XXI, vive-se uma emergência, que mais que ecológica, é uma crise do estilo de pensamento, dos imaginários sociais, dos pressupostos epistemológicos e do conhecimento que sustentaram a modernidade. Uma crise do ser no mundo, que se manifesta em toda sua plenitude: nos espaços internos do sujeito, nas condutas sociais autodestrutivas, nos espaços externos, na degradação da natureza e na qualidade de vida das pessoas (Jacobi, 2005). 


\section{A integração de saberes - caminhos interdisciplinares na educação ambiental e nas geociências}

O longo processo histórico apresentado conduziu a uma grande fragmentação do conhecimento e a uma separação muito profunda entre o homem e a natureza. Em nome da objetividade, precisão e aceitação das teorias científicas, o método científico pregou a "neutralidade" do observador perante seus experimentos e a criação de suas teorias. Tais premissas estão sendo concebidas atualmente, por alguns críticos, como uma das causas da degradação ambiental e da crise da sociedade moderna.

Nessa perspectiva, uma das questões tratadas nos debates sobre a educação ambiental é a crítica à extrema racionalidade da ciência moderna, que desvaloriza outras manifestações humanas como a sensibilidade e a espiritualidade. As ciências revelam uma inadequação de seus pressupostos epistemológicos a uma perspectiva ambiental, o que foi traduzido por Isabel Carvalho (2004, p.111) como a "Crise de uma forma de conhecer e a busca de novos modos de compreender". A crise apontada pela autora refere-se ao contexto indicado antes, e a "busca de novos modos de compreender" refere-se a alguns pressupostos epistemológicos da educação ambiental, dentre os quais encontramos as integrações disciplinares.

A interdisciplinaridade como princípio e atitude constitui foco de discussão para pesquisadores e educadores de vários níveis de ensino, que, ao reconhecerem a complexidade do mundo pós-industrial e o processo de globalização, vivenciados pelos povos do mundo inteiro, estão cientes de que os saberes parcelares não dão conta de resolver problemas que demandam conhecimentos específicos, relacionados a um objetivo comum e central (Pontuschka et al., 2007).

Para uma educação efetiva, é necessário desenvolver uma visão integrada do mundo que nos cerca, uma visão que nos leve a compreender as diversas esferas (hidrosfera, biosfera, litosfera e atmosfera) e suas inter-relações, bem como as interferências geradas pelo homem no meio em que vive.

Os conteúdos das geociências fornecem uma base fundamental para a compreensão dessas inter-relações no espaço e no tempo, oferecendo um panorama da Terra como um sistema vivo e dinâmico. Uma questão central é entender como as geociências contribuem para a formação do professor e dos alunos, considerando as especificidades das ciências e das disciplinas escolares.

Ressaltamos que as geociências, em particular, a geologia, têm uma grande contribuição para uma visão integrada do ambiente, mas ela não faz parte do currículo escolar como uma disciplina, e os conteúdos a ela relativos estão dispersos nas demais disciplinas, em especial Ciências e Geografia. No campo das diversas ciências, apesar de toda a discussão sobre a interdisciplinaridade, ainda se realiza um trabalho compartimentado e isolado com pouca interlocução entre os responsáveis pelos vários ramos do conhecimento.

Segundo Compiani (2005), a falta do desenvolvimento integral das geociências contribui para perpetuar a visão imediatista e utilitarista da natureza. 
Nessa perspectiva, podemos abordar temas como origem e evolução da Terra, formação de seus materiais e de seus ambientes, condições de provável origem da vida, registro sedimentar da história geológica da vida e dos processos de interferência dos processos biológicos no planeta e dos processos geológicos na evolução da vida, condições de concentração dos recursos naturais - minerais, hídricos e energéticos - e suas possibilidades de renovação, condições sustentáveis de utilização dos recursos.

Cuello Gijón (apud Gonçalves, 2006) enfatiza a potencialidade da geologia para servir como núcleo voltado para abordagens interdisciplinares de conteúdo no ensino de crianças e adolescentes, e que as bases metodológicas e epistemológicas, vinculadas ao conhecimento da história da natureza, são especialmente favoráveis ao tratamento sistêmico de temas ambientais, com significativas possibilidades para o trabalho educativo.

Guimarães (2004) nos indica que:

Através do raciocínio e de procedimentos específicos da Geologia é feita a caracterização dos materiais, das formas de energia e das suas interações no espaço e no tempo, definindo-se como um conjunto de parâmetros interrelacionados que servem de padrão de referência do meio físico, construído pelo estudante. Este padrão leva a compreensão do ambiente físico local e de suas relações com o contexto sociocultural, estendendo-a para o contexto mais amplo, até chegar à concepção da Terra como sistema evolutivo complexo, que favoreceu o surgimento e evolução dos organismos, humanidade e que modificam a superfície terrestre.

As dimensões espaço e tempo, que muitas vezes não são tratadas no ensino de ciências, apresentam uma relevância fundamental para a compreensão das questões relativas ao meio ambiente na educação. Apresentam-se como estratégias educativas sem as quais a compreensão integrada do meio ambiente é praticamente impossível.

Segundo Compiani (2007), as escalas e suas dimensões horizontal e vertical são métodos de abordagem que enfatizam os processos de obtenção de informação, pois, dependendo da escala e do ponto de vista de quem está interpretando, um problema socioambiental terá diferentes perspectivas de enquadramento teórico e prático.

Ab’Saber (1991) afirma que a perspectiva integrada exige método, noção de escala, boa percepção das relações entre tempo e espaço, entendimento da conjuntura social e histórica do ambiente que cerca os alunos. Exige ainda respeitar e acreditar no valor da multiplicidade e diversidade de vários mundos que coexistem na sociedade, com o exercício permanente da interdisciplinaridade para enfrentar as questões cotidianas.

A história ambiental de um determinado lugar pode ser mais bem compreendida quando inserida no tempo geológico, a partir do qual se conhecem a história e a origem do planeta Terra, se compreende a dinâmica do sistema em que 
estamos inseridos e do qual fazemos parte, os fenômenos que se sucederam ao longo de bilhões de anos e as transformações ocorridas nesse período. Além disso, serve para promover a percepção dos processos naturais além do ciclo de vida humano e entender o potencial das ações antrópicas sobre o meio natural, ocupando um importante papel nas relações existentes entre o ambiente e a sociedade.

Dessa forma, o tema água deve estar presente no contexto educacional, tanto na educação formal como na não-formal, com enfoque na ética e na formação do cidadão consciente do lugar que ocupa no mundo, num mundo real, dinâmico, que parte do local e se relaciona com o global, onde todas as coisas podem tomar parte de um processo maior, de um sistema integrado. Assim, segundo Compiani (2007), é possível sair do paradigma da causalidade tão enraizado no ensino de ciências e praticar um ensino mais contextualizado, situar espaço-temporalmente os fenômenos, ou seja, levar em conta seu aspecto histórico e assim compreender a complexidade do contexto e causalidade de um fenômeno.

A educação para a água não pode, dessa forma, estar centrada apenas nos usos que fazemos dela, mas na visão de que a água é um bem que pertence a um sistema maior, integrado, que é um ciclo dinâmico sujeito às interferências humanas. Compreender a origem da água, o ciclo hidrológico, a dinâmica fluvial e o fenômeno das cheias, os aqǘferos, bem como os riscos geológicos associados aos processos naturais (assoreamento, enchentes) é essencial para que possamos entender a dinâmica da hidrosfera e suas relações com as demais esferas terrestres.

Acreditamos que a água seja um tema de aproximação dos conhecimentos parcelares profundos e plurais e um tema que desenvolva a prática interdisciplinar.

A construção de um programa que tenha a água como tema gerador, numa proposta de ação interdisciplinar, apoiada nos conceitos fundamentais, no valor explicativo e na função das geociências, deve ser entendida pelos professores nas relações mais profundas entre esse conteúdo e a ação educativa, com envolvimento coletivo, dialógico e troca de saberes.

A escola, inserida nesse contexto social, deve ter como responsabilidade a disseminação do conhecimento, com base na realidade, de forma a caminhar na direção de uma nova ética e maneiras de viver que sejam pertinentes à sociedade. Para Lorieri (2002), a escola deveria propiciar certa interligação entre os conteúdos para a compreensão de determinada realidade que não é fragmentada, mas prenhe de relações, e os projetos interdisciplinares auxiliariam na compreensão dessa realidade complexa e contraditória.

Assim, os temas de geociências como eixos centrais, os quais hoje se encontram disseminados nas diversas disciplinas, com seus ramos físicos, químicos e biológicos, podem ser tratados numa organização interdisciplinar, superando a atual fragmentação. É possível tratar o tema água desde as primeiras séries do Ensino Fundamental até o Ensino Médio, com diferentes estratégias e recursos 
didáticos. Essa abordagem é necessária para atingir os objetivos pretendidos de formar cidadãos conscientes, capazes de julgar e avaliar as atividades humanas que envolvem o uso e a ocupação do ambiente, dentro e fora da comunidade em que estão inseridos.

As metodologias de ensino e aprendizagem devem se valer das diferentes estratégias. Nesse caso, as geociências contribuem para compreender a amplitude, a diversidade e a complexidade do ambiente e a multiplicidade de variáveis que o integram.

As aulas de campo, como enfatizadas por Compiani \& Carneiro (1993), têm um papel pedagógico fundamental, pois é no campo que ocorre o conflito entre o real (o mundo), o exterior e o interior, as idéias e as representações, gerando um contexto único de observação e interpretação da natureza na busca de informações, no entendimento dos fenômenos e na formulação de conceitos explicativos. Segundo os autores, o campo é também o centro de atividades para ensinar o método geral de conceber a história geológica da Terra.

O estudo do meio é uma metodologia de ensino interdisciplinar que pretende desvendar a complexidade de um espaço determinado extremamente dinâmico e em constante transformação, cuja totalidade dificilmente uma disciplina escolar isolada pode dar conta de compreender (Pontuschka et al., 2007).

O estudo do meio como método que pressupõe o diálogo, a formação de um trabalho coletivo e o professor como pesquisador de sua prática, de seu espaço, de sua história, da vida de sua gente, de seus alunos, tem como meta criar o próprio currículo da escola, estabelecendo vínculos com a vida de seu aluno e com a sua própria, como cidadão e como profissional. As autoras ressaltam que um projeto de ensino que usa essa metodologia realiza um movimento de apreensão do espaço social, físico e biológico que se dá em múltiplas ações combinadas e complexas. Para aprender a complexidade do real, faz-se necessária a existência de muitos olhares, da reflexão conjunta e de ações em direção ao objetivo proposto pelo grupo de trabalho (Pontuschka et al., 2007).

O uso dessa metodologia para integrar as disciplinas é ideal para o ensino e a aprendizagem dos alunos, de forma a contextualizar os dados da realidade com os conteúdos. As intervenções pedagógicas de cada disciplina em particular contribuem para o conhecimento dos objetivos do estudo. O tema água pode ser abordado de várias maneiras no estudo do meio, dependendo dos objetivos propostos.

As perspectivas indicadas anteriormente estão sendo tratadas no projeto "Elaboração de conhecimentos escolares e curriculares relacionados à ciência, à sociedade e ao ambiente na escola básica com ênfase na regionalização a partir dos resultados de projeto de Políticas Públicas", realizado na bacia hidrográfica do Rio Anhumas, em Campinas. O projeto é uma parceria entre professores e pesquisadores do Instituto Agronômico de Campinas (IAC), Faculdade de Educação (FE) da Universidade de São Paulo (USP), Instituto de Geociências 
(IG) e Instituto de Biologia (IB) da Universidade de Campinas (Unicamp) e das escolas estaduais Adalberto Nascimento e Ana Rita Godinho Pousa. O projeto é coordenado pelo Prof. Dr. Maurício Compiani e conta com financiamento da Fapesp e da Petrobras.

No projeto está sendo trabalhada a perspectiva do professor-pesquisador, ou seja, de que o professor reflita sobre sua própria prática. Nessa abordagem, pensamos como a ciência é construída e como ela se articula com as questões políticas, econômicas e sociais. Assim, a interdisciplinaridade tem ocorrido na articulação entre os professores envolvidos no projeto e as relações ocorrerão no decorrer da prática de pesquisa do professor. Consideramos que as pesquisas educacionais se constituem em três perspectivas essenciais: na subjetividade do professor-pesquisador, ou seja, em sua dimensão individual; na constituição do coletivo de professores e na articulação do grupo; e, por fim, em todo o contexto em que está sendo construída a pesquisa.

Quanto ao contexto de elaboração, o projeto está sendo realizado em âmbito local na bacia hidrográfica do Ribeirão Anhumas. Essa dimensão ambiental é extremamente relevante em projetos educacionais que tratem de perspectivas ambientais.

\section{A importância da bacia hidrográfica na educação}

A complexidade que envolve o tema água na escola exige do professor uma capacidade de explorar o ambiente de forma contextualizada.

Os estudos podem partir do conhecimento das bacias hidrográficas como eixo norteador e resgatar a história ambiental local, a fim de desenvolver nos estudantes uma visão integrada dos diferentes fatores - naturais e antrópicos - que condicionam as transformações ambientais.

As bacias hidrográficas são espaços que se caracterizam pelos seus fatores físicos, mas são influenciadas diretamente pela ocupação humana e pela ação dos diversos grupos sociais que nela se instalam. Seja em meio rural seja em urbano, os usos da água na bacia hidrográfica são determinados pelos grupos que a ocupam, e sua interferência no meio físico ocorre em razão dos interesses desses grupos. As bacias são, então, palco de processos naturais ao mesmo tempo que sofrem modificações pelo homem.

Trabalhar no âmbito da bacia hidrográfica promove o entendimento do contexto, do singular e histórico, e a partir do qual se criam situações e estratégias de aprendizagem. A bacia hidrográfica pode ser tomada como local das atividades voltadas para ensinar o método geral de conceber a história da água no planeta. Conhecimentos sobre a origem da água, o ciclo hidrológico, os aqǘferos, a relação precipitação-vazão servem para inseri-la num amplo e complexo processo de interação na natureza e relacioná-la com a sociedade (usos múltiplos, ocupação de áreas de mananciais, riscos geológicos, poluição, contaminação e gestão dos recursos hídricos). 
A bacia hidrográfica pode ser o eixo condutor de diversas disciplinas, pode propiciar o desenvolvimento de práticas escolares científicas, funcionar como agente integrador das disciplinas na construção de uma visão abrangente da natureza. Além disso, é na bacia hidrográfica que os diversos atores sociais se encontram para um a negociação dos usos múltiplos.

Para Tucci (1993, 1999), a bacia hidrográfica é uma área de captação natural da água da precipitação que faz convergir os escoamentos para uma única área de saída, seu exutório. Uma seção de um rio define a sua bacia hidrográfica.

A bacia hidrográfica é, na concepção de Tundisi et al. (1988, p.314-5):

uma unidade importante na investigação científica, treinamento e uso integrado de informações para demonstração, experimentação, observação em trabalho real de campo. Uma bacia pode ser utilizada como laboratório natural em que a contínua e reforçada atividade estimula o desenvolvimento de interfaces e aumenta progressivamente a compreensão de processos e fenômenos de uma forma globalizada e não compartimentalizada.

A bacia hidrográfica é adotada na Política Nacional de Recursos Hídricos (Lei n.9433/97) como unidade territorial que abrange cursos de água que são catalogados como "principal" e ou "tributário", mas não está necessariamente abrangendo os aqüíferos. A lei faz distinção entre bacia hidrográfica e bacia hidrológica, a qual é a unidade fisiográfica ou geológica que contém pelo menos um aqüífero de extensão significativa.

As bacias hidrográficas constituem-se em unidades básicas de planejamento do uso, da conservação e recuperação dos recursos naturais, definido pela Lei Nacional da Política Agrária (Lei n.8171/91).

A definição dada pelas leis de uma unidade integrada na qual os fenômenos se inter-relacionam foi fundamental na adoção de políticas públicas de gestão dos recursos hídricos, dentre elas a da criação dos Consórcios e dos Comitês de Bacias Hidrográficas e a Agência Nacional das Águas. Essa visão integrada, já consagrada nas políticas públicas, não pode deixar de ser adotada pela escola quando trata do tema água.

No contexto escolar, a bacia hidrográfica não deve ser vista somente como o rio principal e seus afluentes, mas, sim, como todo volume de onde se verificam as trocas de matéria e energia e a dinâmica suscitada principalmente pela água, incluindo tanto as formas de superfície como o lençol freático. A evaporação, os agentes de intemperismo que atuam sobre as formas de relevo e a ação humana devem ser estudados quando se trata de bacia hidrográfica examinada sob o aspecto de delimitação de um volume num espaço com uma história humana nele impressa (Silva, 2003, in Pontuschka et. al., 2007).

Partindo da perspectiva das políticas públicas ambientais, estão se desdobrando ações educacionais que têm envolvido a comunidade em estratégias participativas de conservação e recuperação ambiental. 
$\mathrm{Na}$ literatura encontramos diversos projetos desenvolvidos em escolas com diferentes abordagens do tema água, mas todos articulando o currículo ao contexto da bacia hidrográfica: Tundisi et al. (1988, 1996), Leal \& Sudo (1998); Silva (2003, in Pontuschka et al., 2007); Romera e Silva (2004); Compiani (2006); Hagy \& Villanova (2007); De La Corte \& Figueiredo (2007); Lucatto \& Talamoni (2007).

É importante ressaltar que projetos que apresentam uma contextualização dos problemas que envolvem a água apresentam resultados mais eficazes quanto à questão da conscientização de professores e alunos, que passam a olhar para a realidade de maneira complexa. Os autores citados trazem essa experiência com resultados muito positivos, ressaltando a melhora na compreensão do conteúdo e mudanças de atitude dos envolvidos no processo de ensino e aprendizagem.

Braga et al. (2003) ressalta que é necessário educar para o ambiente, e somente a partir de ações locais, da sensibilização e da conscientização dos indivíduos como cidadãos participantes no processo de construção de uma nova sociedade é que podemos modificar o destino dos problemas globais que assolam o planeta, e a água é uma questão primordial.

Para Romera e Silva (2004), a educação e os projetos de capacitação devem facilitar a percepção e a avaliação das contradições locais, sendo a construção do conhecimento um fator de mediação na gestão de conflitos entre culturas, comportamentos diferenciados e interesses de grupos sociais, para que as transformações pretendidas pela sociedade se realizem.

\section{Educando nas águas do Pirajuçara: uma proposta de educação ambiental}

Com a preocupação de tratar a questão da água a partir das dimensões espaço-temporal, de forma interdisciplinar e tendo a bacia hidrográfica como foco principal, como discutido ao longo deste artigo, foi proposto o curso de atualização "Educando nas águas do Pirajuçara: uma proposta de Educação Ambiental" promovido pelo grupo TEIA-USP (Laboratório de Educação e Ambiente) composto por alunos e professores da Faculdade de Educação (FE), do Instituto de Geociências (IGc) e da EACH (Escola de Artes, Ciências e Humanidades da Universidade de São Paulo). Faremos aqui um breve relato desse curso em andamento numa proposição de articulação entre as perspectivas teóricas discutidas neste artigo com a prática da formação de professores.

Os objetivos do curso são trabalhar a bacia hidrográfica do Pirajuçara, a partir dos aspectos físicos, históricos, sociais, econômicos e ambientais, a participação social, a avaliação do significado de degradação ambiental nos recursos hídricos e a percepção da realidade local. $\mathrm{O}$ curso pretende fornecer subsídios para a formulação de projetos e ações de educação ambiental nas escolas. Visa também estimular a troca de informações e experiências entre os participantes e o desenvolvimento de habilidades na utilização de meios de comunicação virtual para a formação de uma rede multiplicadora voltada para mudanças de atitude que visem ao uso sustentável da água. 
A proposição do curso está de acordo com o objetivo principal do TEIA de constituir um espaço de pesquisa-ação e produção de conhecimento, reflexão e debate sobre práticas e políticas de educação ambiental no Brasil. Mediante a construção de um espaço interdisciplinar, o grupo propõe a participação direta da comunidade acadêmica no debate e na elaboração de políticas públicas voltadas ao conjunto da sociedade, ao aproximar o conhecimento gerado junto aos organismos públicos e privados e a comunidade em geral por meio de parcerias (www.teia.fe.usp.br).

O conteúdo do curso foi estruturado em quatro módulos, articulados entre os membros do grupo, e definido da seguinte forma:

1) Educação ambiental, sustentabilidade e participação. Trata-se de uma abordagem sobre as relações entre educação e meio ambiente com ênfase nos temas da sustentabilidade e da participação social como eixos que estimulam o desenvolvimento de um pensamento crítico. O módulo prioriza leituras que promovam um aprofundamento teórico das práticas de educação ambiental e permitam a aquisição de um repertório sobre a cultura da sustentabilidade em suas múltiplas dimensões, considerando as práticas sociais, o tema da cidadania e a dimensão cultural num contexto permeado pela ampliação dos problemas ambientais.

2) Ciclo da água no planeta - aspectos teóricos e metodológicos. Aborda a origem da água no planeta, o ciclo hidrológico, destacando-se as principais fases e características, água subterrânea, aqüíferos; conceitos de bacia hidrográfica, traçado e parâmetros básicos; interferências do homem nos processos naturais ocasionando enchentes e escorregamentos; aspectos físicos da bacia hidrográfica do Pirajuçara. Esse módulo é articulado a uma oficina temática de estudo da bacia hidrográfica pela construção de maquetes.

3) Aspectos sociais, institucionais e econômicos da água. Nesse espaço é analisada a política das águas, destacando a Política Nacional dos Recursos Hídricos, a situação no Estado de São Paulo e, especificamente, na Região Metropolitana de São Paulo. Também é dado destaque para os aspectos econômicos de cobrança da água e outros mecanismos e para a análise sobre o impacto dos problemas sociais na qualidade de vida e na gestão dos recursos hídricos.

4) A água: aspectos históricos e geográficos. A abordagem metodológica utilizada aqui é da relação histórica entre ciência, tecnologia, sociedade e ambiente. É feita uma contextualização histórica sobre os usos da água durante o período colonial brasileiro, destacando-se os condicionantes naturais para a navegação que configuraram a formação do Império português entre os séculos XV-XVIII. Além disso, destacamos a configuração das bacias hidrográficas brasileiras associadas às condicionantes de navegação fluvial como fatores determinantes para a expansão territorial e da divisão política da América portuguesa. A água também foi um elemento estruturador da urbanização, em que havia um planejamento construção de cidades em pontos estratégicos na costa brasileira 
e na foz de alguns rios durante o período colonial. Além disso, alguns traçados urbanos também seguiam a configuração dos rios, pela importância da água em todas as atividades do cotidiano das populações. Na perspectiva tecnológica, a água representou grande importância no desenvolvimento agrícola e industrial no Brasil, pois era uma das principais fontes de força motriz para os engenhos agroindustriais, de mineração e a separação dos minérios. Essa construção histórica é realizada com a análise de textos em associação com imagens, como cartas marítimas e fluviais; perfis de cidades; planos urbanísticos.

Os módulos são integrados pela articulação entre os formadores e, especialmente, pela proposição de uma atividade de campo integrada. O roteiro percorrerá a bacia do Pirajuçara e seus principais afluentes, com a observação in loco e discussão dos aspectos do meio físico, dos aspectos históricos, de uso e ocupação, dos problemas sociais e ambientais. Serão coletados dados com registro fotográfico e elaboração de um roteiro que possa ser usado pelos professores em suas aulas, com a possibilidade de levar os alunos para realização de atividades, como estudo do meio. Serão feitas observações da qualidade das águas dos rios na bacia, da forma de ocupação e dos problemas ambientais gerados pelo nãoplanejamento da ocupação da bacia, as obras estruturais realizadas pelo poder público (retificação de canais, piscinões).

O curso está em andamento, mas uma breve avaliação de seu desenvolvimento pode ser feita em razão do atendimento à demanda dos professores e da necessidade que eles apresentam em desenvolver uma visão integrada da realidade. O curso está fornecendo subsídios para que os professores possam rever seus currículos, reformulando-os numa perspectiva local, e cria oportunidade da prática da interdisciplinaridade, da integração e da discussão do papel da escola diante das realidades ambientais.

\section{Considerações finais}

Morin $(2003,2004)$ afirma que, para prepararmo-nos para o enfrentamento da crise em que a sociedade atual está inserida e das futuras gerações, é necessário mudarmos nossa forma de ver o mundo e partirmos para uma compreensão da complexidade da realidade. Segundo o autor, nossa civilização e, por conseguinte, nosso ensino privilegiam a separação dos conteúdos em detrimento da ligação, e a análise em detrimento da síntese desune os objetos entre si. Com o isolamento dos objetos de seu contexto natural e do conjunto do qual faz parte, é uma necessidade cognitiva inserir um conhecimento particular em seu contexto e situá-lo em seu conjunto, o que é imperativo na educação.

A contextualização desenvolve um pensamento que situa todo acontecimento, informação ou conhecimento em relação de inseparabilidade com seu meio ambiente - social, cultural, econômico, político e natural - e incita a perceber como esse o modifica ou o explica de outra maneira, tornando-se um pensamento complexo. 
Sendo assim, passa a ser primordial entender a complexidade da relação homem-natureza na realidade local. Essa compreensão na escola, por meio da formação de professores e dos alunos, é que poderá fazer a diferença na formação de indivíduos críticos, participativos, prontos a enfrentar os problemas ambientais e uma possível crise dos recursos naturais disponíveis, dentre eles a água.

Referências bibliográficas

AB'SABER, A. N. (Org.) Conceituando educação ambiental. Rio de Janeiro: CNPq; Museu de Astronomia e Ciências Afins, 1991.

ABRANTES, P. Imagens de natureza, imagens de ciência. Campinas: Papirus, 1998.

BRAGA, A. R. et al. Educação ambiental para gestão de recursos hídricos. Livro de Orientação ao Educador. Americana: Consórcio PCJ, 2003. 25 lp., il.

BRASIL. Lei n.8.171, de 1991. Lei Nacional da Política Agrária. Diário Oficial da União, Brasília, 18.1.1991.

. Lei n.9.433, 8 jan. 1997. Política Nacional de Recursos Hídricos. Diário Oficial da União, Braślíia, 1997.

CARVALHO, I. C. M. Educação ambiental: a formação do sujeito ecológico. São Paulo: Cortez, 2004.

COMPIANI, M. Geologia/Geociências no Ensino Fundamental e a Formação de Professores. Revista do Instituto de Geologia USP. Public. Espec., São Paulo, v.3, p.13-30. 2005 .

Ensaios de interdisciplinaridade no Ensino Fundamental com Geologia/Geociências. In: PONTUSCHKA, N. N.; OLIVEIRA A. U. (Org.) Geografia em perspectiva. 3.ed. São Paulo: Contexto, 2006.

. O lugar e as escalas e suas dimensões horizontal e vertical nos trabalhos práticos: implicações para o ensino de ciências e educação ambiental. Ciência \& Educação, v.13, n.1, p.29-45, 2007.

COMPIANI, M.; CARNEIRO, C. R. Os papéis didáticos das excursões geológicas. Enseñanza de las Ciencias de La Tierra, v.1.2, p.90-8, 1993.

DE LA CORTE, M.; FIGUEIREDO, R. L. A trajetória de uma inovação curricular entre duas disciplinas (Biologia e Geografia) a partir do ambiente local norteado pelo ciclo da água. In: I SIMPÓSIO DE PESQUISA EM ENSINO E HISTÓRIA DE CIÊNCIAS DA TERRA. III Simpósio Nacional sobre Ensino de Geologia no Brasil. Campinas, SP, 2007. p.45-50.

GONÇALVES, P. V. Ensino de Ciência do Sistema Terra e formação continuada de professores em efetivo exercício. Relatório Técnico. Unicamp, 2006.

GRÜN, M. Ética e educação ambiental: a conexão necessária. Campinas: Papirus, 1996. (Coleção Magistério: Formação e Trabalho Pedagógico).

GUIMARÃES, E. M. A contribuição da Geologia na construção de um Padrão de Referência do Mundo Físico na Educação Básica. Revista Brasileira de Geociências, n.34, p.87-94, 2004.

GUIMARÃES, M. Educação ambiental crítica. In: MINISTÉRIO DO MEIO AM- 
BIENTE. Identidade da educação ambiental brasileira. Org. Philippe Layrargues. Brasília, 2004. p.25-34.

Armadilha paradigmática na educação ambiental. In: LOUREIRO, C. F. L. B. et al. (Org.) Pensamento complexo, dialética e educação ambiental. São Paulo: Cortez, 2006.

HAGY, R. D.; VILlANOVA, G. L. Ciclo da água e a urbanização: um estudo do meio (microbacia de drenagem do córrego dos Campos) com alunos da terceira série do ensino médio. In: I SIMPÓSIO DE PESQUISA EM ENSINO E HISTÓRIA DE CIÊNCIAS DA TERRA. III Simpósio Nacional sobre Ensino de Geologia no Brasil. Campinas, SP, 2007. p.119-24.

JACOBI, P. R. A cidade e o meio ambiente. São Paulo: Annablume, 1999.

Educação ambiental: o desafio da construção de um pensamento crítico, complexo e reflexivo. Educação e Pesquisa, v.31, n.2, p.233-50, 2005.

LEAL, A. C.; SUDO, H. Educação ambiental e gestão de recursos hídricos: experiências na graduação e educação continuada de professores do ensino fundamental. In: SIMPÓSIO INTERNACIONAL SOBRE GESTÃO DE RECURSOS HÍDRICOS, 1998, Gramado, RS. Anais... Gramado: ABRH, 1998.

LORIERI, M. A. Filosofia: fundamentos e métodos. São Paulo: Cortez, 2002.

LOUREIRO, C. F. B. Educação ambiental transformadora. In: MINISTÉRIO DO MEIO AMBIENTE. Identidade da educação ambiental brasileira. Org. Philippe Layrargues. Brasília, 2004. p.65-84.

LUCATTO, L. G.; TALAMONI, J. L. B. A construção coletiva interdisciplinar em educação ambiental no ensino médio: a microbacia hidrográfica do Ribeirão dos Peixes como tema gerador. Ciência \& Educação, v.13, n.3, p.389-98, 2007.

MORIN, E. Os sete saberes necessários à educação do futuro. Trad. Catarina Eleonora F. da Silva e Jeanne Sawaya; revisão técnica de Edgard de Assis Carvalho. 8.ed. São Paulo: Cortez; Brasília: Unesco. 2003. p.118.

- A cabeça bem-feita: repensar a reforma, reformar o pensamento. Trad. Eloá Jacobina. 9.ed. Rio de Janeiro: Bertrand Brasil, 2004. p.128.

PONTUSCHKA, N. N. et al. Para ensinar e aprender Geografia. São Paulo: Cortez, 2007. (Coleção Docência em Formação. Série Ensino Fundamental).

ROMERA E SILVA, P. A. Água: quem vive sem? 2.ed. São Paulo: FCTH/CT-Hidro (ANA, CNPq/SNRH), 2004.

ROSSI, P. Os filósofos e as máquinas. São Paulo: Cia. das Letras, 1989.

SÃO PAULO (Estado). Secretaria da Educação. Coordenadoria de Estudos e Normas Pedagógicas. Água Hoje e Sempre: consumo sustentável. Secretaria da Educação. São Paulo: SE/Cenp, 2004. 256p., il.

SOFFIATI, A. As raízes da crise ecológica atual. Ciência e Cultura, v.39, n.10, p.951-4, 1992.

TUCCI, C. E. M. Hidrologia: ciência e aplicação. Porto Alegre: Ed. da Universidade; ABRH; Edusp, 1993.

Água no meio urbano. In: REBOUÇAS, A. C. et al. (Org.) Águas doces no Brasil: capital ecológico, uso e conservação. São Paulo: Escrituras, 1999. 
TUNDISI, J. G. Roteiro de excursão à bacia hidrográfica do ribeirão do Lobo e à represa do Lobo (BROA). São Carlos: CDCC-USP, 1996. (Projeto EDUC@R. Educação Ambiental através do estudo de bacia hidrográfica e qualidade da água).

. Novas perspectivas para a gestão de recursos hídricos. Revista USP, São Paulo, n.70, p.24-35, 2006.

TUNDISI, J. G. et al. A utilização do conceito de bacia hidrográfica como unidade para atualização de professores de Ciências e Geografia: o modelo Lobo (Broa) - Brotas/Itirapina. In: . (Org.) Liminologia e manejo de represas. São Carlos: USP, 1988. p.311-57. (Série Monografia).

RESUMO - A água como tema no contexto educacional é abordada a partir de diversas perspectivas. Diante das discussões em relação à crise socioambiental atual, acreditamos que a educação para a água deva ser realizada a partir da abordagem das dimensões espacial e temporal, considerando nesta última o tempo geológico e a história humana, sem a qual não é possível enfrentar a fragmentação do conhecimento que predomina no ambiente escolar. A abordagem do local, tendo como unidade de estudo a bacia hidrográfica, auxiliada pelos conteúdos das geociências e por metodologias interdisciplinares, proporciona uma visão integrada e contextualizada do tema para a construção do conhecimento.

PALAVRAS-CHAVE: Água, Interdisciplinaridade, Bacias hidrográficas, Educação ambiental, Geociências.

ABSTRACT - The water as subject in the education context should be boarded from several perspectives. With a view to the current discussions regarding the socio-environmental crisis, we believe that the education for the water should be carried out from two dimensions: spatial and temporal, the last one considering geological time and human history and without these perspectives are not possible to face the fragmentation of the knowledge that predominates in scholar environment. For a construction of a new knowledge, the hydrographic basin as a unity of study provides an integrated vision, aided by Geosciences and interdisciplinary methodologies.

KEYWORDS: Water, Interdisciplinary, Hydrographical basin, Environmental education, Geosciences.

Denise de La Corte Bacci é professora doutora do Departamento de Geologia Sedimentar e Ambiental, Instituto de Geociências - IGc/USP. @- bacci@igc.usp.br

Ermelinda Moutinho Pataca é professora doutora do Departamento de Metodologia de Ensino e Educação Comparada, Faculdade de Educação - FE/USP.

$@$ - ermelinda.pataca@gmail.com

Recebido em 3.7.2008 e aceito em 9.7.2008. 